\title{
Lithospheric-scale structures in New Guinea and their control on the location of gold and copper deposits
}

\author{
L. T. White ${ }^{1,2}$, M. P. Morse ${ }^{2, *}$, and G. S. Lister ${ }^{2}$ \\ ${ }^{1}$ Southeast Asia Research Group, Department of Earth Sciences, Royal Holloway University of London, Egham, Surrey, UK \\ ${ }^{2}$ Research School of Earth Sciences, The Australian National University, Canberra, ACT, Australia \\ * current address: Geoscience Australia, Canberra, Australia
}

Correspondence to: L. T. White (lloyd.white@ rhul.ac.uk)

Received: 1 July 2013 - Published in Solid Earth Discuss.: 22 October 2013

Revised: 28 January 2014 - Accepted: 7 February 2014 - Published: 31 March 2014

\begin{abstract}
The locations of major gold and copper deposits on the island of New Guinea are considered by many to be controlled by a series of transfer faults that strike $\mathrm{N}-\mathrm{S}$ to NE$\mathrm{SW}$, perpendicular to the long axis of the island. The premise is that these faults dilate perpendicular to the regional stress field, forming conduits for metalliferous gases and fluids to drop out of solution. However, the data on which this idea was first proposed were often not presented or, when the data were presented, were of poor quality or low resolution. We therefore present a review of the existing structural interpretations and compare these with several recently published geophysical data sets to determine if the mineralization controlling transfer faults could be observed. These data were used to produce a new lineament map of New Guinea. A comparison of the lineaments with the location of major gold and copper deposits indicates there is a link between the arc-normal structures and mineralization. However, it is only those deposits that are less than 4.5 million years old that could be associated with these structures. Gravity and seismic tomography data indicate that some of these structures could penetrate deep levels of the lithosphere, providing some support to the earlier idea that the arc-normal structures act as conduits for the younger mineral deposits of New Guinea. The gravity data can also be used to infer the location of igneous intrusions at depth, which could have brought metal-bearing fluids and gases closer to the Earth's surface. These regions might be of interest for future exploration campaigns, particularly those areas that are crosscut by deep, vertical faults. However, new exploration models are needed to explain the location of the deposits that are older than $5 \mathrm{Ma}$.
\end{abstract}

\section{Introduction}

The exploration for metalliferous deposits around the world presents a challenge as there is still much to learn about the processes that concentrate metals in particular areas. Many of the largest mineral deposits around the world were found from detailed exploration campaigns around areas where the "old timers" panned the streams and sunk shafts, particularly in the search for gold. There is a major geological challenge, however, in understanding the bigger picture, and why there are regions of the globe that are particularly well endowed with concentrations of precious metals. In the pursuit of this goal, geologists typically devise models that attempt to explain why some metals are more concentrated in particular regions. One such model is that gold and copper deposits are often found along strike of other deposits (e.g. along a line or a lineament) (cf. Richards et al., 2000). However, the problem here is that several deposits must be discovered before a line can be drawn between the points. So, lineaments are only proposed retrospectively, after several deposits have been identified. The effectiveness of this technique is questionable. Yet, these lineament style analyses are commonly used by the minerals exploration industry, particularly on the island of New Guinea because it is home to some of the world's richest gold and/or copper deposits (e.g. Grasberg, Ok Tedi, Frieda River, Porgera and Wafi-Golpu) (Fig. 1a).

The idea that part of the Papuan Fold Belt in central New Guinea was dissected by arc-normal transfer faults was proposed in Hill (1991). This work focussed on the structural geology of the region from a hydrocarbon perspective rather than copper and gold exploration. It presented data from 

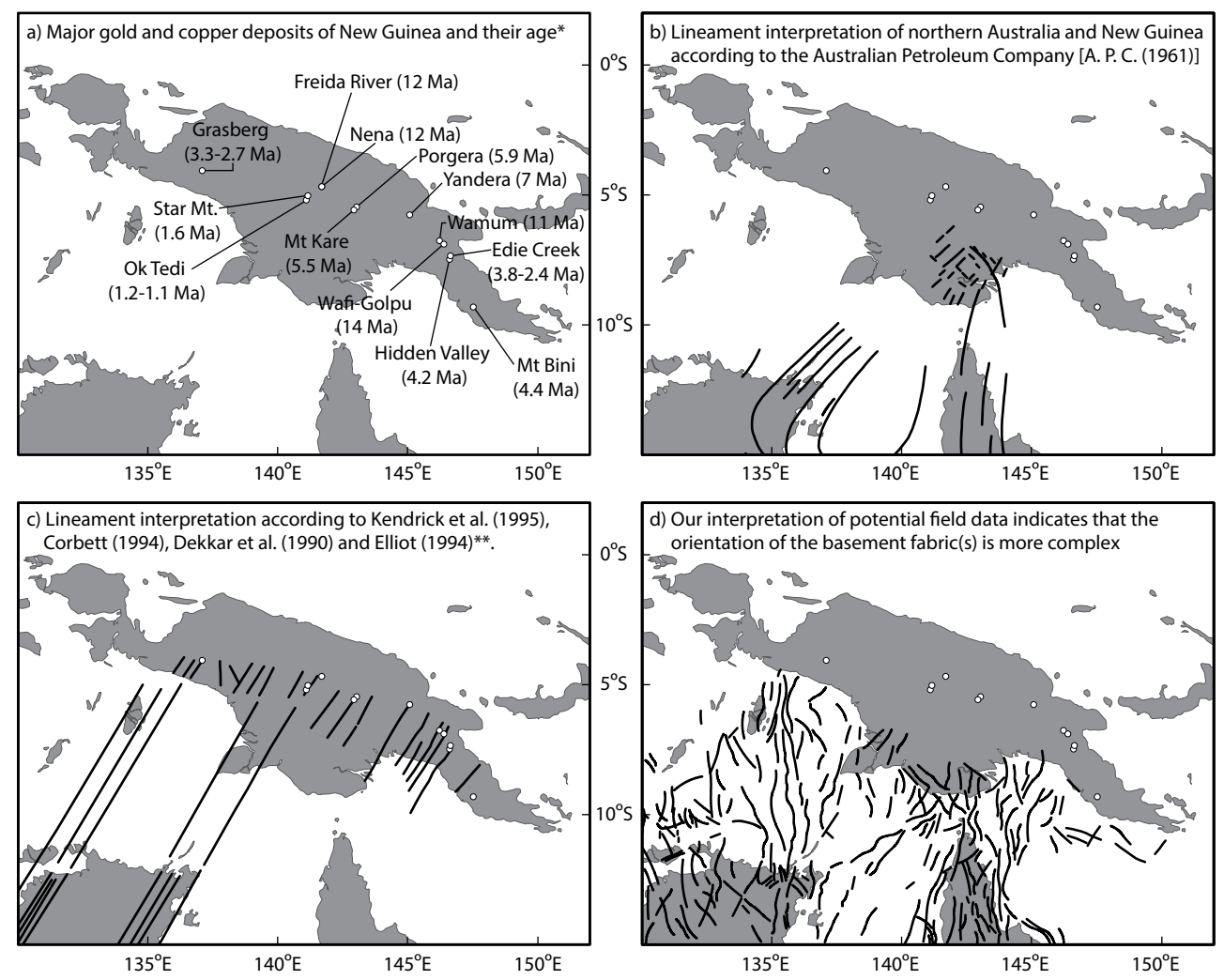

Fig. 1. Maps of northern Australia and New Guinea showing (a) the location of major gold and copper deposits and the age of mineralization; (b) the location of lineaments according to the Australian Petroleum Company (A. P. C., 1961), who suggested that the basement fabric of northern Australia persisted across the Arafura Sea and into southern Papua New Guinea; (c) the location of lineaments that were identified by different studies conducted along the length of New Guinea (Hill et al., 1991; Corbett et al., 1994; Dekker et al., 1994 and Kendrick et al., 1995). These interpretations assumed that NNE striking structures of the Australian mainland could be extrapolated across the Arafura Sea and into New Guinea (in this case the structures that are shown here for northern Australia were proposed by Elliot (1994)). (d) However, our interpretation of magnetic data (Milligan (2010): Magnetic Map of Australia, 5th Edition) and gravity data (Pavlis et al., 2008, 2013; this paper) indicates that the orientation of the basement fabric is much more complex than previous workers proposed. * Mineralization ages were taking from the compilation of Garwin et al. (2005). ** Image was adapted from a figure presented in Hill et al. (1996).

geological mapping campaigns and structural analyses that showed that four NNE-trending lineaments could be drawn through the SE limit of the Muller Anticline, the NW limit of the Tari Basin, the NW limit of the deformed Mio-Pliocene strata in the Andabare Plataeu, the SE limit of the Om metamorphic terrane, the NE limit of the Miocene Maramuni igneous province and offset of the NE-SW-trending Papuan Ultramafic Belt. This model drew on the idea that northern Australia had a dominant NNE-SSW-oriented crustal fabric that ran across the Arafura Sea and into southern New Guinea (Fig. 1b) (A. P. C., 1961), where the faults were said to be reactivated lateral ramps that were displaced during a period of shortening in the Neogene. This structural interpretation was also proposed to explain results from apatite fission-track analyses that indicated that parts of Papua New Guinea (PNG) had experienced varying rates of uplift (Hill and Gleadow, 1989). Further support for the model was provided by Davies (1990, 1991), who showed that NNE-SSW striking clusters of mantle-derived intrusives and volcanics occurred near Bosavi (Fig. 2a). This chain of igneous rocks is referred to as the Bosavi Transfer Zone (Smith, 1990) or the "Bosavi Lineament" (e.g. Hill et al., 2004, 2010). A second magmatic lineament was also identified to the west, drawn through Anju (south) to Ananadi (north) (Fig. 2b). As the magmatic centres along these lineaments young to the south, Davies (1990) calculated that the magmatic front migrated at a rate of 5-8 mm per year (Fig. 2c-d). This rate of movement is an order of magnitude lower than that of the Australian plate (e.g. DeMets et al., 1990), so this magmatism was said to be controlled by a local decrease in pressure in the mantle beneath a deep crustal tensional structure oriented parallel to the axis of maximum horizontal stress (i.e. a NNE-SSW striking transfer fault) (Davies et al., 1990).

Additional arc-normal transfer structures were proposed to exist in New Guinea, east and west of those that were identified by Hill (1991) and Davies et al. (1990, 1991). These arcnormal structures were defined on the basis of the interpretation of gravity data and the orientation of geomorphological 

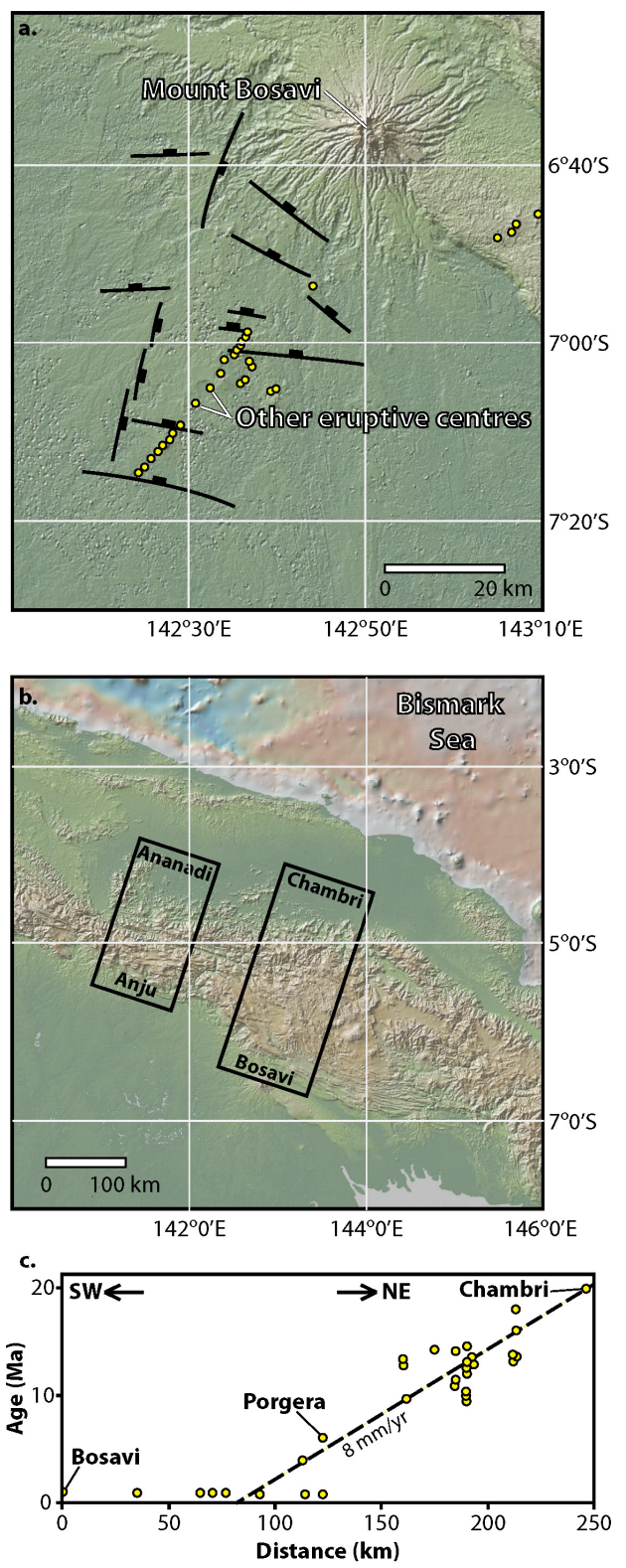

d.

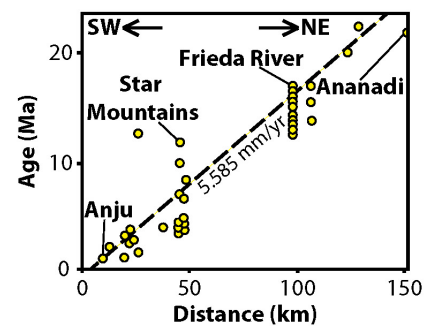

Fig. 2. A chain of volcanics near Bosavi was identified by Davies $(1990,1991)$ who showed that magmatism in this region progressed from north to south across Papua New Guinea. This pattern is observed (a) locally where active volcanism occurs at Mount Bosavi and in smaller eruptive centres to the south, and (b) regionally. Davies (1990) drew to cross sections from Ananadi to Anju and Chambri to Bosavi to show that (c-d) the volcanic front migrated at a rate of 6-8 $\mathrm{mm} \mathrm{yr}^{-1}$. Figure was modified from Davies (1990). The basemap in (a) and (b) is from the Global Multi-Resolution Topography (GMRT) data set (Ryan et al., 2009). features such as drainage lines identified from Landsat imagery and aerial photography (Fig. 1c) (e.g. Dekker et al., 1990; Corbett, 1994; Kendrick et al., 1995; Gow and Walshe, 2005; Hill et al., 2008; 2010). Several workers then drew on the link between the structural and magmatic lineaments (e.g. Hill 1991; Davies et al., 1990, 1991) and the location of some of New Guinea's copper and gold deposits. The NNE-SSW striking lineaments were considered to dilate perpendicular/obliquely to the regional maximum principal stress direction associated with convergence between the Australian and Pacific plates. These dilationary zones were said to focus the ascent of evolved magmas and magmatic and metalliferous fluids from deep-crustal reservoirs to nearer the Earth's surface (e.g. Corbett, 1994; Kendrick et al., 1995; Hill et al., 1996, 2002; Richards, 2000). It did not take long before a NNE-SSW striking lineament was identified to intersect each copper and/or gold deposit in New Guinea (Corbett, 1994; Kendrick et al., 1995; Hill et al., 2002; Gow and Walshe, 2005) (Fig. 1c). These were proposed according to the interpretation of various forms of geophysical data.

Yet, while there has been much interest in mapping the arc-normal structures, it is difficult to evaluate if they actually exist. This is because the geophysical data that were used to interpret the structures is often not presented or, if data were shown, the resolution/quality was too low to clearly interpret the location of a geological structure. While there is some geological evidence that supports the existence of NNE-SSW-trending lineaments (e.g. Hill, 1991; Hill et al., 2008,2010 ), we were skeptical as to whether all of the proposed transfer structures exist in New Guinea. So we were curious as to whether these structures were mappable using higher-resolution geophysical data that were not available when the lineament concept was originally proposed. We therefore discuss the background behind the concept of the lineaments in New Guinea and evaluate the earlier lineament interpretations against modern geophysical data sets.

\section{Geophysical data that were used in this study}

In this section we discuss the data that were used, including information about the source and resolution of the data, as well as how the data were processed and interpreted. Please note that we were unable to access the same gravity and magnetic data that were used in the earlier studies, so we instead used publicly accessible data, or data that we obtained permission to use.

\subsection{Topography/bathymetry}

Several workers proposed lineaments on the basis of interpretations of topographic data (Corbett, 1994; Kendrick et al., 1995; Gow and Walshe, 2005). We obtained topographic data for New Guinea from the Global Multi-Resolution Topography (GMRT) model (Ryan et al., 2009) (Fig. 3) as well 
as the Consultative Group on International Agricultural Research Consortium for Spatial Information (CGIAR-CSI), who reprocessed NASA's Shuttle Radar Topographic Mission (SRTM) global digital elevation data set (Version 4.0) (Jarvis et al., 2008) (Fig. 4).

The spatial resolution of the GMRT is variable as it ties together multiple sources of data. The resolution of the onshore topography data ranges between 30 and $90 \mathrm{~m}$, whilst the resolution of bathymetric data is generally $\sim 100 \mathrm{~m}$ (and up to $\sim 50 \mathrm{~m}$ in some coastal areas). In comparison, the CGIARCSI SRTM data have a uniform resolution of $90 \mathrm{~m}$, but the coverage is limited to land above sea level. The variable $\sim 30-100 \mathrm{~m}$ resolution of these data indicate that structural features can be mapped to a sufficient level of detail for a regional interpretation such as presented here, that is, provided that these geomorphological features actually represent faults.

The GMRT data were manipulated online using GeoMapApp (www.geomapapp.org). The CGIAR-CSI SRTM data are served as a series of tiles to the community from CGIARCSI's website (http://srtm.csi.cgiar.org). The relevant tiles were downloaded and were merged using ArcGIS 10.0.

We used the GMRT data set (Ryan et al., 2009) to assess whether lineaments could be observed in regions such as the Arafura Sea between Australia and New Guinea (e.g. Fig. 3). We used the SRTM data to evaluate the interpretation of Gow and Walshe (2005), who proposed that some NE-trending lineaments could be identified in PNG if only the 10, 100 and $1000 \mathrm{~m}$ topographic contours were drawn on a map (Fig. 4a). To do this we orthorectified the map that was shown in Gow and Walshe (2005) and compared this with the same selection of topographic contours generated from the SRTM data and displayed in ArcGIS (Fig. 4b).

\subsection{Magnetics}

To our knowledge there are no publicly available regional onshore magnetic data sets that cover New Guinea, so we could not produce a structural interpretation for the island. The EMAG2, Earth Magnetic Anomaly Grid (Maus et al., 2009), covers much of the offshore region that surrounds New Guinea (see Supplement file 1), and Geoscience Australia continue to publish maps of their compiled magnetic data sets (e.g. Milligan, 2010), but these do not extend far enough to the north to be useful for a structural interpretation of onshore New Guinea. These data sets do provide useful information about the orientation of fabric(s) along northern Australia, so these were used in conjunction with gravity data (see Sect. 2.3) to assess the orientation of lineaments along northern Australia, the Arafura Sea and southern New Guinea (Fig. 1d).

We accessed two smaller-scale high-resolution aeromagnetic data sets that cover parts of the PNG Central Highlands and the Papuan Peninsula (Figs. 3 and 5) that were collected by Fugro Ltd for the World Bank between 2006 and 2008. These data were collected in north-south-oriented lines with 400-500 $\mathrm{m}$ line spacing and a terrain clearance of $100 \mathrm{~m}$ during a helicopter-borne survey. The aero-magnetic data grids have a cell size of $100 \mathrm{~m}$ by $100 \mathrm{~m}$ such that these data can effectively show magnetic anomalies with wavelengths of $200 \mathrm{~m}$. A raster was produced from the magnetic data using a minimum curvature, exploration industry standard interpolation. The Central Highlands data set covers an area that encompasses the Porgera (Au), Mt Kare (Au) and Yandera (Cu-Mo) deposits (Fig. 5), and therefore the northern segment of the Porgera-Mt Kare lineament (Hill, 1991). So, these data were used to determine if these lineaments could be identified with regional magnetic data. This involved an examination of the reduced-to-pole magnetic grid. We also examined the same grid after applying an upward continuation residual (UCR) filter (Jacobsen, 1987; Morse, 2010).

The UCR filter is a method of frequency separation that generates a high-frequency residual data set by subtracting a higher upward continued (UC) potential field data set from a lower UC or original (zero level) of the same data set. Upward continuation simulates the effect of measuring the potential field at a higher (larger) distance from the source (ground level), so this calculation effectively filters out the anomalies of smaller and shallower sources, producing a smoother, longer wavelength data set (a higher UC produces a smoother data set relative to a lower UC). The high-frequency signal in an UC or original data set can be accessed by subtracting the higher, smoother (longer wavelength) upward continued signal. This arguably produces a data set that shows significantly enhanced geological features (Morse, 2010). In this case, we generated new grids by subtracting (1) the $1 \mathrm{~km} \mathrm{UC}$ grid from the original magnetic data grid, (2) the $5 \mathrm{~km} \mathrm{UC}$ grid from the $1 \mathrm{~km} \mathrm{UC}$ magnetic data grid, and (3) the $5 \mathrm{~km} \mathrm{UC}$ grid from a $2 \mathrm{~km}$ UC magnetic data grid (Fig. 5).

\subsection{Gravity}

In addition to the examination of topographic and magnetic data sets, we also interpreted free-air and Bouguer gravity grids to determine if these data could be used to delineate arc-normal structures (Fig. 6). The grids used were spatial subsets of the global Earth Gravitational Model (EGM2008) (Pavlis et al., 2008), covering the greater New Guinea region. These data were downloaded from the Bureau Gravimétrique International's (BGI) data portal (http://bgi.omp.obs-mip.fr/index.php/eng/Data-Products/ Grids-and-models/Regional-gravity-anomaly-grids). The Bouguer data that were downloaded had been corrected using the FA2BOUG code that was proposed by Fullea et al. (2008). This included a topographic correction that was applied up to a distance of $167 \mathrm{~km}$ using the $1.0 \times 1.0$ arc-minute ETOPO1 digital elevation model (Amante and Eakins, 2009). The gravity data have a spatial resolution of 
Table 1. Details of the UCR grids that were generated from the BGI Bouguer gravity data where one upward continued grid $(\operatorname{grid}(X))$ (that was generated by simulating the measurement being made $X \mathrm{~km}$ above the original surface) was subtracted from another upward continued grid $(\operatorname{grid}(Y))$ (that was generated by simulating the measurement being made $Y \mathrm{~km}$ above the original surface).

\begin{tabular}{ll}
\hline $\begin{array}{l}\text { Upward continued } \\
\text { height }(X \mathrm{~km})\end{array}$ & $\begin{array}{l}\text { Upward continued } \\
\text { height }(Y \mathrm{~km})\end{array}$ \\
\hline 30 & 1 \\
40 & 5 \\
50 & 10 \\
80 & 20 \\
100 & 40 \\
\hline
\end{tabular}

$2.5 \times 2.5$ arc minutes $(\sim 4-5 \mathrm{~km})$. While this is quite coarse, they are the best publicly available data (to our knowledge) that cover onshore New Guinea. These data were used to produce a grid with a minimum curvature interpolation.

The UCR filter (see Sect. 2.2) (Jacobsen, 1987; Morse, 2010) was also applied to the Bouguer data set. In the case of the UCR Bouguer gravity data, new UCR grids were generated by subtracting the original Bouguer gravity grid upward continued $X$ kilometres above the surface, from the same grid upward continued $Y$ kilometres above the surface (i.e. $\operatorname{grid}(Y)$ minus $\operatorname{grid}(X))$ (Figs. 7-8). The $\mathrm{X}$ and $\mathrm{Y}$ heights for the UCR grids that were generated are shown in Table 1.

\subsection{Additional image processing of magnetic and gravity data prior to structural interpretation}

The magnetic and gravity data sets were loaded in ER Mapper 7.1 before any structural interpretation began. Three duplicate gravity or magnetic images were draped on top of one another. The base layer was used to display the "intensity" of the magnetic or gravity signal. The intensity layer was illuminated with a light source from the north $\left(000^{\circ}\right)$, northeast $\left(045^{\circ}\right)$, east $\left(090^{\circ}\right)$ and southeast $\left(135^{\circ}\right)$ with an inclination angle of $30-40^{\circ}$ so that we could highlight different orientations of geological structures, where a new image file was generated for each sun angle. The middle and highest layers are duplicate images shaded with a gradient fill. The only difference between the two layers is that the highest layer was made partially transparent to better enhance the data in shadowed areas.

\subsection{Seismic Tomography}

Seismic tomography has proven a useful tool to map geological structures in the lower crust and mantle. We used the global $P$ wave seismic tomography data set of $\mathrm{Li}$ et al. (2008) and the global $S$ wave seismic tomographic data set of Debayle et al. (2005) to determine if any arc-normal lineaments were imaged with tomography data and therefore major crustal structures since these structures reportedly focus metal-bearing fluids from such depths (Corbett, 1994; Kendrick et al., 1995; Hill et al., 1996, 2002). The tomographic data were imported as a grid of points into ArcGIS 10.0. Tomograms were produced by applying a spline interpolation to the point data for different depth slices $(68,113$ and $203 \mathrm{~km}$ ) (Fig. 11). The data were also contoured at discrete intervals to aid the identification of any linear structural features (Fig. 11). The spatial resolution of this data set is estimated to be $\sim 100 \mathrm{~km}$ in the best sampled regions of the upper mantle (Li et al., 2008). The station coverage is relatively good across New Guinea and northern Australia (cf. Figure 1 of Li et al., 2008), but this coverage is less dense than other parts of the world, so the spatial resolution is likely to be greater than $100 \mathrm{~km}$. This means that the tomography data will not be useful in identifying a particular fault or lineament in New Guinea, but they should still be useful in identifying if there are any major discontinuities in the lower crust and upper mantle.

\section{Results}

\subsection{Topographic data}

Our examination of the GMRT bathymetric and topographic data did not identify any regional NE to $\mathrm{N}$ striking lineaments in northern Australia, the Arafura Sea or in New Guinea (Fig. 3). We were also unable to identify any clear NE to $\mathrm{N}$ striking lineaments using SRTM data when using all of the data, or with selected contours as advocated by Gow and Walshe (2005). Our regional comparison is shown Fig. 4. Gow and Walsh (2005) suggested that NNE-trending lineaments could be readily identified when the 10, 100 and $1000 \mathrm{~m}$ topographic contours were drawn (Fig. 4a), but this is not evident when the same contours are drawn using the SRTM data (Fig. 4b). This means that the contours that were used by Gow and Walshe (2005) were smoothed or were derived from topographic data with a much lower spatial resolution. Considering these points, we concluded that topographic data are not the best data to use to discriminate arcnormal lineaments. While topographic data do have a use in identifying structural features, we did not use them any further in this study as topographic data cannot be used to determine if arc-normal structures are deep-level features that could focus metalliferous fluids. 


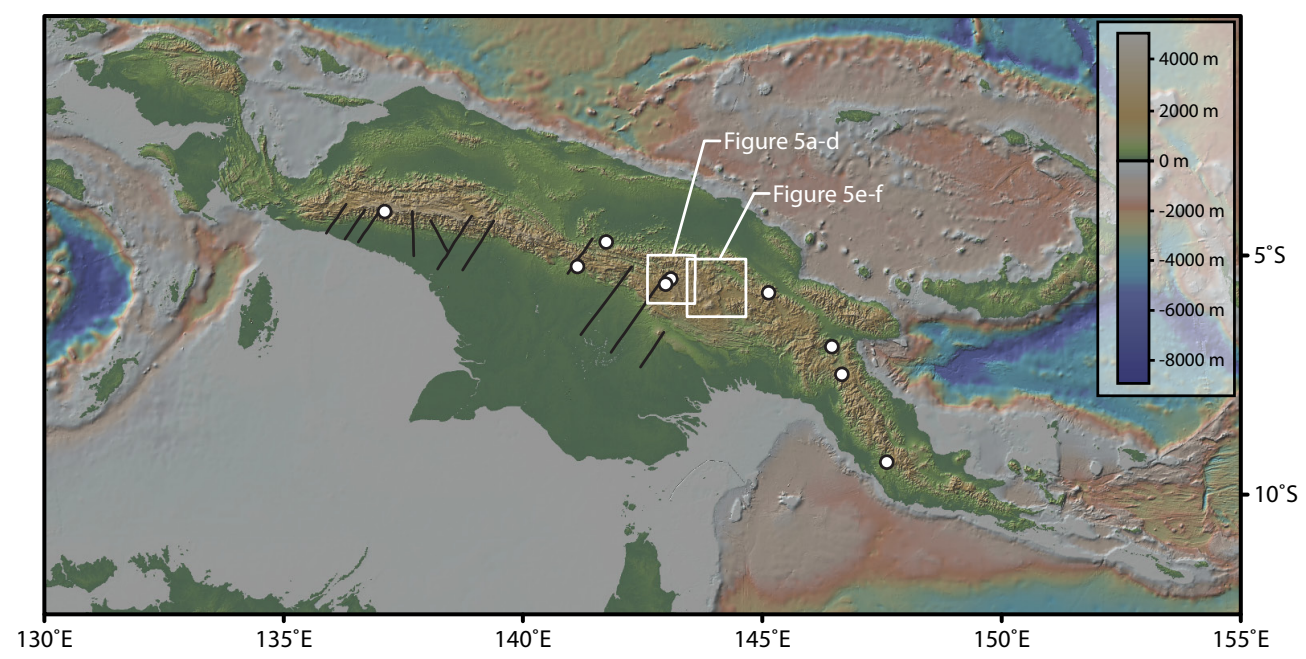

Fig. 3. A topographic and bathymetric map of New Guinea and the Arafura Sea using the Global Multi-Resolution Topography (GMRT) data set (Ryan et al., 2009) shows that there are no pronounced NNE striking lineaments. The location of New Guinea's copper and gold deposits (white circles) and the NNE-trending lineaments (thin black lines) that were proposed by Hill (1991) and Kendrick et al. (1995) are also shown.

\subsection{Magnetics}

The regional magnetic data UCR grid shows that the original regional magnetic data contain many subtle N-S- to NW-SE-oriented lineaments (Fig. 5a-b). We are unsure as to whether these lineaments represent orthogonal/polygonal faults (Fig. 5a-b), chevron-type folds (Fig. 5b), if they reflect a topographic feature, or if these do not represent geological features, and are a data artefact. As these lineaments are not visible in the lower-frequency UCR filtered data (Fig. 5c-d), it indicates that they do not occur deep in the crust.

We also observed several subtle NE striking magnetic features in the region directly east of Porgera (Fig. 5e). These lineaments were also not imaged in the lower-frequency UCR grids, indicating that they are not deep structures (Fig. 5f). We suspect that these lineaments could represent shallow dykes, veins or fractures given that they were only observed around volcanic centres (Fig. 5e).

Although there are possible NNE striking faults and dykes, these are subtle structural features. We envisaged that the lineament that was proposed to intersect the Mt Kare and Porgera gold deposits (Corbett, 1994; Kendrick et al., 1995) would be more pronounced in magnetic data. However, these data indicate the Mt Kare-Porgera lineament is not a magnetic feature, or that this particular lineament does not exist (Fig. 5a).

\subsection{Gravity}

The free-air and Bouguer gravity data indicate that NNEtrending lineaments occur in various regions of New Guinea (Fig. 6a-b). Yet these images also show that there are many other lineaments with different orientations. This is partic- ularly the case along the northern margin of Australia, the Arafura Sea and southern New Guinea where N-S-oriented lineaments are more pronounced than lineaments with other orientations (Figs. 1d, 6a-b).

The arc-normal faults that were proposed by Hill (1991) and Kendrick et al. (1995) were overlain on the free-air and Bouguer gravity data. This shows that some of the previously proposed NNE-trending lineaments correspond with sharp boundaries in the gravity data, yet many of the proposed lineaments do not (Fig. 6a-b).

While there are some lineaments that are apparent in all of the gravity grids - for example, the N-S- to NE-SW-oriented structures that cut across the Arafura Sea into southern New Guinea (Fig. 6) - we found that it was much easier to identify lineaments in the UCR filtered gravity grids relative to the free-air and Bouguer gravity data. The UCR filtered images highlight distinct edges of gravity anomalies, many of which could be interpreted as lineaments, and indeed arcnormal faults (Figs. 7-8). Some of these distinct breaks in gravity anomalies correspond with the lineaments proposed by earlier workers (e.g. Hill, 1991; Kendrick et al., 1995). Some of the distinct changes in gravity could also be interpreted as faults, as they show an apparent sense of displacement (Fig. 9).

\subsection{A revised regional lineament map from the interpretation of gravity data}

An updated lineament map of New Guinea was produced by examining each of the UCR filtered magnetic and gravity grids (Fig. 10). These grids indicate that NNE-trending lineaments do occur in New Guinea, particularly in central and northern parts of the island. However, these structures are not 


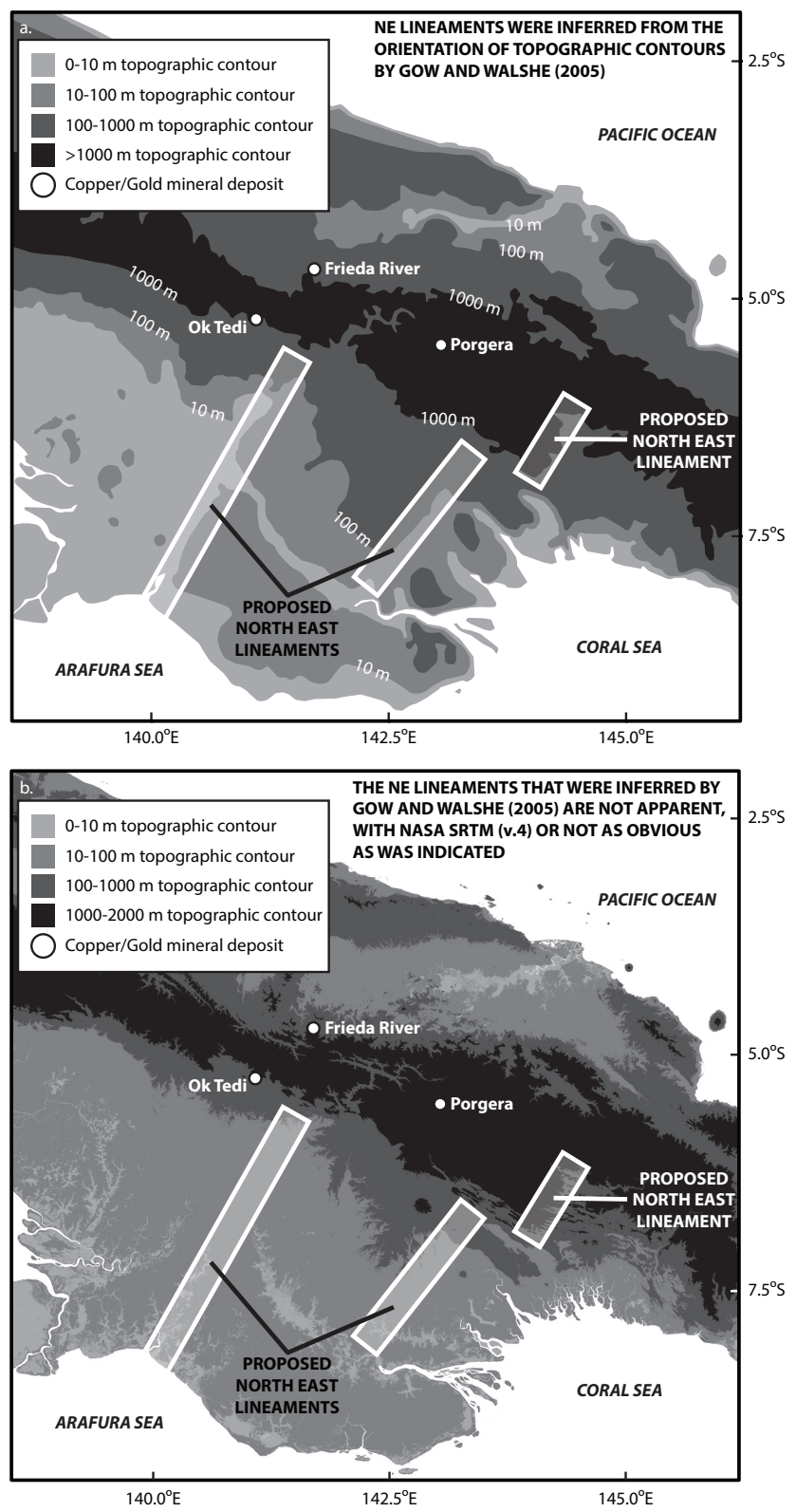

Fig. 4. (a) Gow and Walshe (2005) examined the topography of Papua New Guinea at three elevation contours (10, 100 and $1000 \mathrm{~m}$ ). From these, they saw that there were several pronounced NE striking trends. (b) However, these features are not observed when the same elevation contour intervals are generated using the NASA Shuttle Radar Topographic Mission (SRTM) (version 4) data.

as laterally extensive as earlier workers proposed. The geophysical data also indicate that there are multiple orientations of fabrics in the northern Australian lithosphere, and this conflicts with the idea that there is a pervasive NNE fabric between northern Australia and New Guinea (e.g. Fig. 1c). This indicates that the lineaments observed in New Guinea are not related to those in northern Australia, or that the older
Table 2. List of $\mathrm{Cu}-\mathrm{Au}, \mathrm{Cu}-\mathrm{Mo}, \mathrm{Au}$ and $\mathrm{Au}-\mathrm{Ag}$ deposits in New Guinea, their age and whether a NNE-trending structure that was identifiable in gravity and magnetic data dissects the region of the deposit. The deposit ages were taken from Garwin et al. (2005).

\begin{tabular}{lcl}
\hline Deposit & Intersecting lineament & Deposit age \\
\hline Ok Tedi & Yes & $1.2-1.1 \mathrm{Ma}$ \\
Star Mountain & Yes & $1.6 \mathrm{Ma}$ \\
Grasberg & Possibly & $3.3-2.7 \mathrm{Ma}$ \\
Edie Creek & Yes & $3.8-2.4 \mathrm{Ma}$ \\
Hidden Valley & Yes & $4.2 \mathrm{Ma}$ \\
Mt Bini & Yes & $4.4 \mathrm{Ma}$ \\
Mt Kare & No & $5.5 \mathrm{Ma}$ \\
Porgera & No & $5.9 \mathrm{Ma}$ \\
Yandera & No & $7.0 \mathrm{Ma}$ \\
Wamum & No & $11.0 \mathrm{Ma}$ \\
Frieda River & No & $12.0 \mathrm{Ma}$ \\
Nena & No & $12.0 \mathrm{Ma}$ \\
Wafi-Golpu & No & $14.0 \mathrm{Ma}$ \\
\hline
\end{tabular}

structures of the Australian lithosphere have been folded or rotated into their current orientation. Our structural interpretation also indicates that only some of the mineral deposits overlie (or are at least proximal to) an arc-normal lineament (Fig. 10/Table 2). These include Star Mountain, Ok Tedi, Hidden Valley, Edie Creek, Mt Bini and possibly Grasberg. It is interesting to note that these deposits are relatively young $(<4.5 \mathrm{Ma})$ and the deposits that are older than 4.5 Ma do not correspond with arc-normal structures (Table 2).

\subsection{Seismic tomography}

The $P$ wave seismic tomography grids show that there is a $\mathrm{NE}-\mathrm{SW}$ - to N-S-oriented boundary between what we interpret to represent cold Australian lithosphere (Fig. 11). This boundary is most pronounced in the 113 and $203 \mathrm{~km}$ depth tomograms (Fig. 11b-f), but it is also visible in the $68 \mathrm{~km}$ depth slice. The tomographic feature is also imaged at the same depths in the global $S$ wave tomographic data set of Debayle et al. (2005) (Supplement file 2). We are confident that this tomographic anomaly represents a lithological/mantle structure as it is imaged in multiple tomographic data sets.

When our revised lineament interpretation (Fig. 10) is overlain on the 68, 113 and $203 \mathrm{~km}$ tomograms (Fig. 11b, d, f), it clearly shows that several NNE-trending lineaments follow the western edge of the tomographic anomaly (Fig. 11b, $\mathrm{d}, \mathrm{f}$ ). It is therefore possible that the geometry of this mantle structure could control the orientation of faults/lineaments observed at, or near, the surface. 

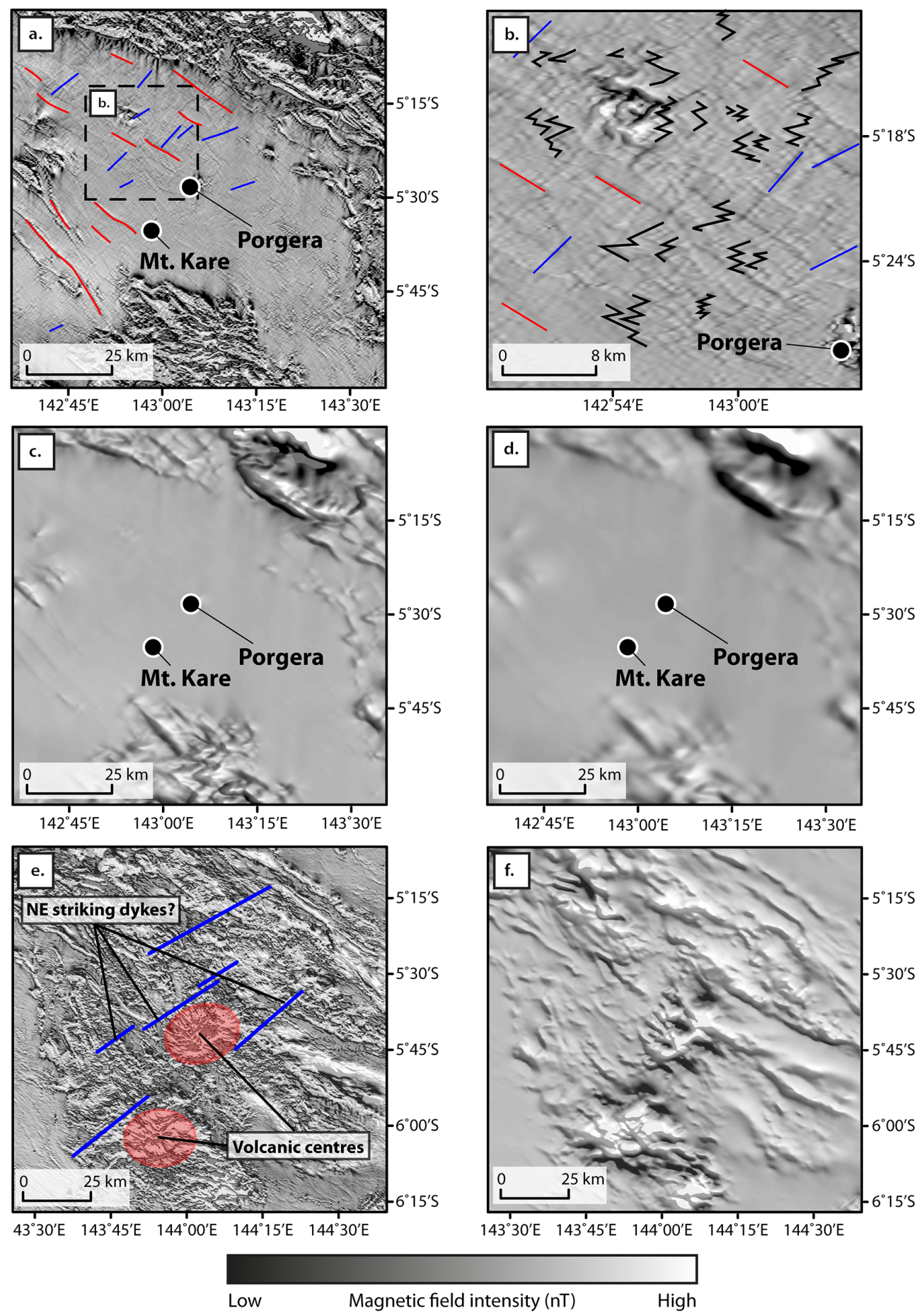

Fig. 5. An upward continuation residual (UCR) filter was applied to regional aeromagnetic data to determine if northeast-trending lineaments could be observed near the Mt Kare and Porgera Au deposits. While NE-SW and NW-SE striking lineaments are observed (a, b, e) in the images where the $1 \mathrm{~km}$ upward continuation grid was subtracted from the original data, the same structures were not observed in the longer-frequency ("deeper") UCR grids, where the $5 \mathrm{~km}$ upward continuation grid was subtracted from the $1 \mathrm{~km}(\mathbf{c}$ and f) and $2 \mathrm{~km}$ (d) upward continuation grids. This indicates that the northeast-trending lineaments are shallow structures. Images (a-d) were generated with an illumination angle from the east. Images (e-f) were generated with an illumination angle from the northeast. 

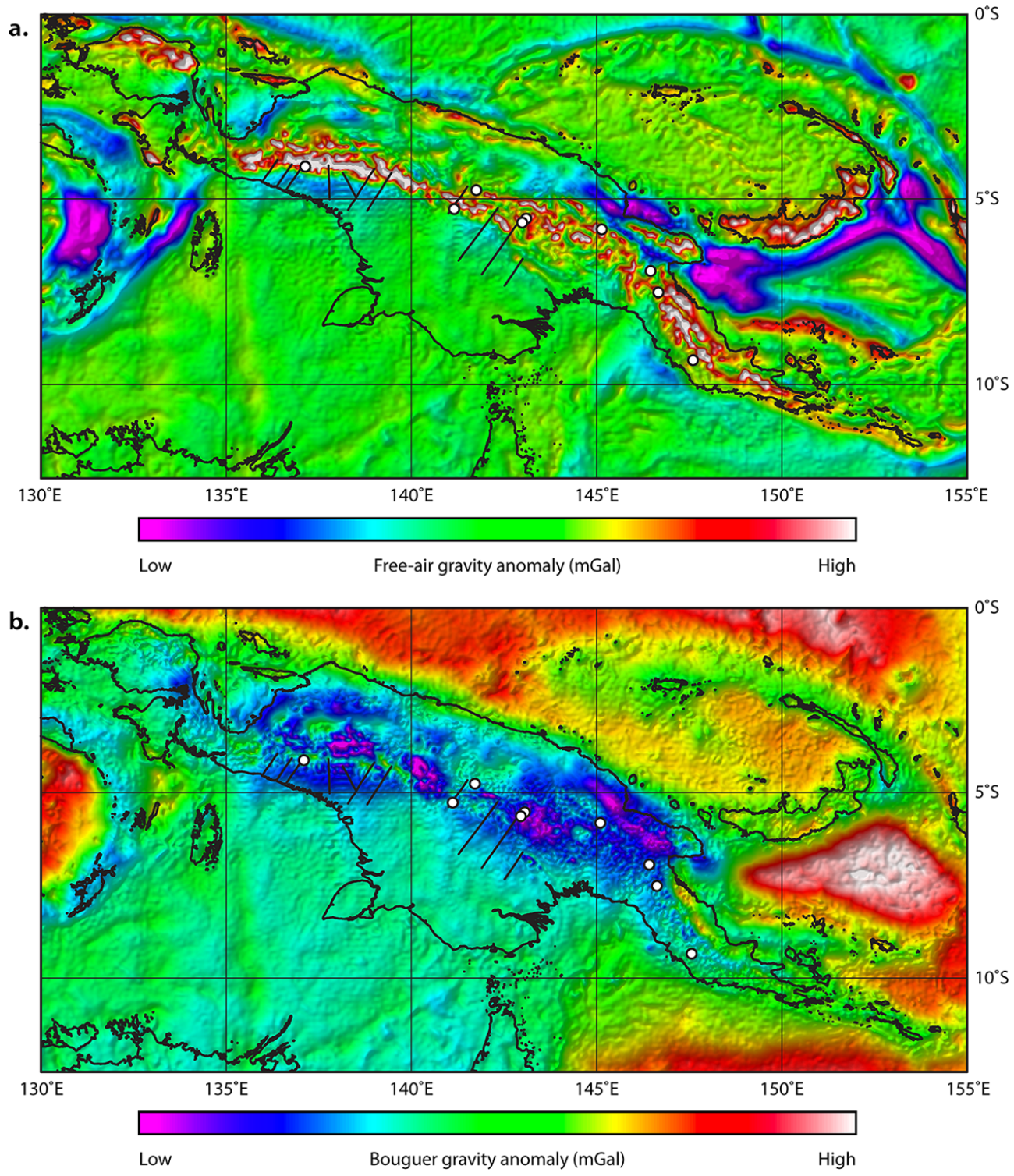

Fig. 6. (a) Free-air and (b) Bouguer gravity data sets obtained from the Bureau Gravimetrique Internationale (BGI) show that there are several major N-S- and NE-SW-trending structures cutting across the Arafura Sea. These data also indicate that the majority of structures in southern New Guinea trend N-S. However, there are some NNE-SSW-trending structures in central and northern New Guinea. This indicates that if any NNE-SSW striking faults occur in New Guinea, they are perhaps unrelated to the inherited fabric of the Australian lithosphere. The light source in these images is from the southeast to highlight NE-trending structures. The same images were generated with different illumination angles to interpret lineaments with other orientations. The location of major $\mathrm{Au} / \mathrm{Cu} / \mathrm{Ag} / \mathrm{Mo}$ deposits is shown as white circles (See Fig. 1a for more details). The NNE-trending lineaments that were proposed by Hill (1991) and Kendrick et al. (1995) are shown as thin black lines.

\section{Discussion}

\subsection{Structural interpretation of geophysical data}

The application of a UCR filter to gravity and magnetic data were useful for interpreting lineaments when compared to using the original free-air gravity, Bouguer gravity and reduced-to-pole magnetic data. The use of different sun angle orientations to highlight lineaments of different orientations was an essential part of the process. This is because regional structural interpretations of geophysical images where only one sun angle orientation is used will bias which structures are drawn/interpreted. 

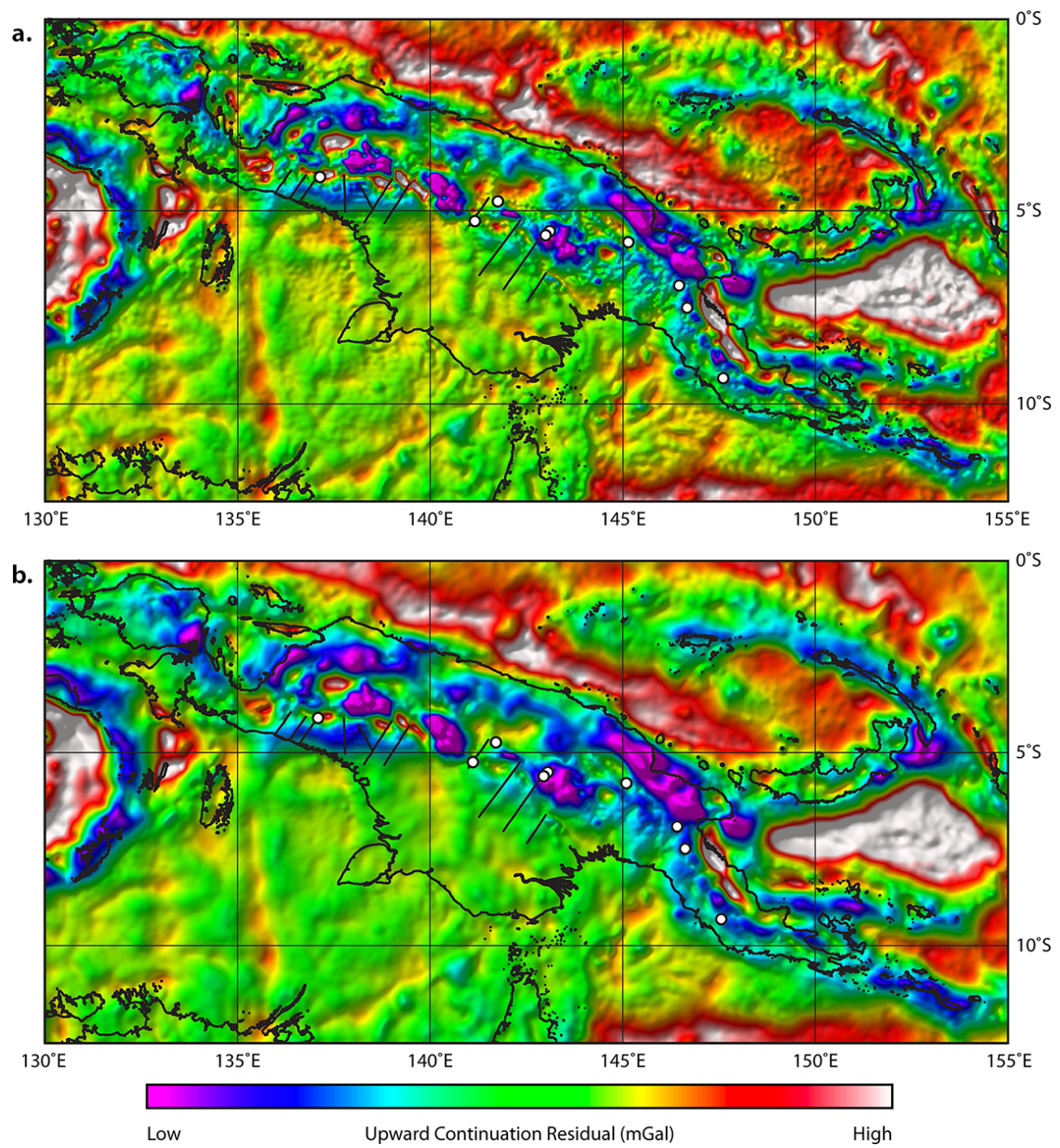

Fig. 7. Upwards continuation residual (UCR) filter applied to the BGI Bouguer gravity data. The Bouguer gravity data were calculated as if they were collected by a measurement at 5, 10, 40 and $50 \mathrm{~km}$ a.s.l., and new grids were produced by (a) subtracting the $40 \mathrm{~km}$ grid from the $5 \mathrm{~km}$ grid, and (b) subtracting the $50 \mathrm{~km}$ grid from the $10 \mathrm{~km}$ grid. The illumination direction that was used in (a) and (b) is from the southeast. This was used to highlight any NNE-trending structures. The same grids were generated with different illumination angles to interpret lineaments with other orientations. The location of major $\mathrm{Au} / \mathrm{Cu} / \mathrm{Ag} / \mathrm{Mo}$ deposits is shown as white circles (See Fig. 1a for more details). The NNE-trending lineaments that were proposed by Hill (1991) and Kendrick et al. (1995) are shown as thin black lines.

While the geophysical data do not prove that a lineament is a geological structure (e.g. a fault), we are confident that many of the interpreted lineaments are geological structures as some of the gravity anomalies are offset (e.g. Fig. 9). However, it is also likely that some of the lineaments that were interpreted could reflect features that are not geological structures. Such issues will be refined through time as new, higher-resolution data become available.

\subsection{Arc-normal faults and their control on mineralization}

Our aim was to present a methodical and systematic method of mapping lineaments in a way that the reader could clearly evaluate our work and come to their own judgement as to whether arc-normal faults exist in New Guinea. We were initially skeptical about the existence of any arc-normal transfer structures in New Guinea as the evidence that was proposed in support of these structures was often not shown, or was not clearly presented. However, our analysis of various geophysical data do indeed support that some arc-normal lineaments occur along the length of the island (Fig. 10). 

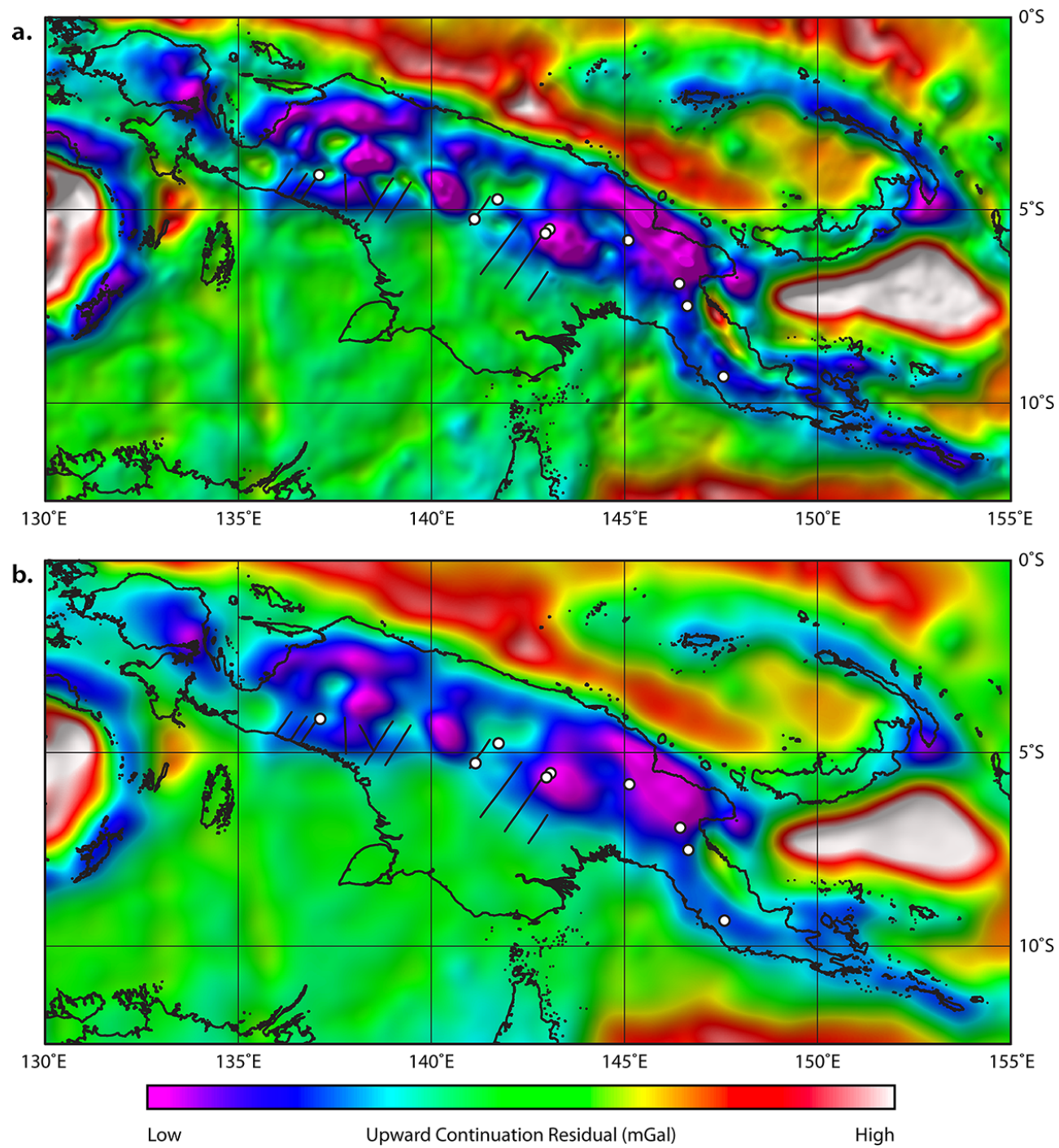

Fig. 8. Upwards continuation residual (UCR) filter applied to the BGI Bouguer gravity data. The Bouguer gravity data were calculated as if they were collected by a measurement at 20,40, 80 and $100 \mathrm{~km}$ a.s.1., and new grids were produced by: (a) subtracting the $80 \mathrm{~km}$ grid from the $20 \mathrm{~km}$ grid, and (b) subtracting the $100 \mathrm{~km}$ grid from the $40 \mathrm{~km}$ grid. The illumination direction that was used in (a) and (b) is from the southeast. This was used to highlight any NNE-trending structures. The same grids were generated with different illumination angles to interpret lineaments with other orientations. The location of major $\mathrm{Au} / \mathrm{Cu} / \mathrm{Ag} / \mathrm{Mo}$ deposits is shown as white circles (See Fig. 1a for more details). The NNE-trending lineaments that were proposed by Hill (1991) and Kendrick et al. (1995) are shown as thin black lines.

In regards to timing, Hill (1991) proposed that the arcnormal transfer faults first formed as lateral ramps along with arc-parallel normal faults during a phase of extension during the Late Cretaceous-Palaeocene (100-56 Ma). The arcparallel normal faults were later inverted during a phase of shortening in the Late Miocene to Pliocene $(\sim 11-2.5 \mathrm{Ma})$, and the arc-normal lateral ramps were reactivated as strikeslip faults/transfer zones at the same time. This deformation is marked by the offset of the Eocene-middle Miocene Darai Limestone (Hill 1991; Davies 2012). This time limit on the movement of the transfer faults is interesting considering that we found that the arc-normal structures only intersect the de- posits that are less than 5 million years old (Fig. 10 and Table 2).

\subsection{Inherited basement fabric}

The orientation of the arc-normal lateral ramps (otherwise known as accommodation, or transfer, zones; cf. Gawthorpe and Hurst, 1993) was said to be controlled by a ProterozoicPalaeozoic fabric that was the same orientation along northern Australia, the Arafura Sea and New Guinea (Hill 1991) (Fig. 1b-c). Accommodation zones are common in various extensional basins around the world (e.g. Gawthorpe and Hurst 1993; Longley et al., 2002; McClay et al., 2002); 


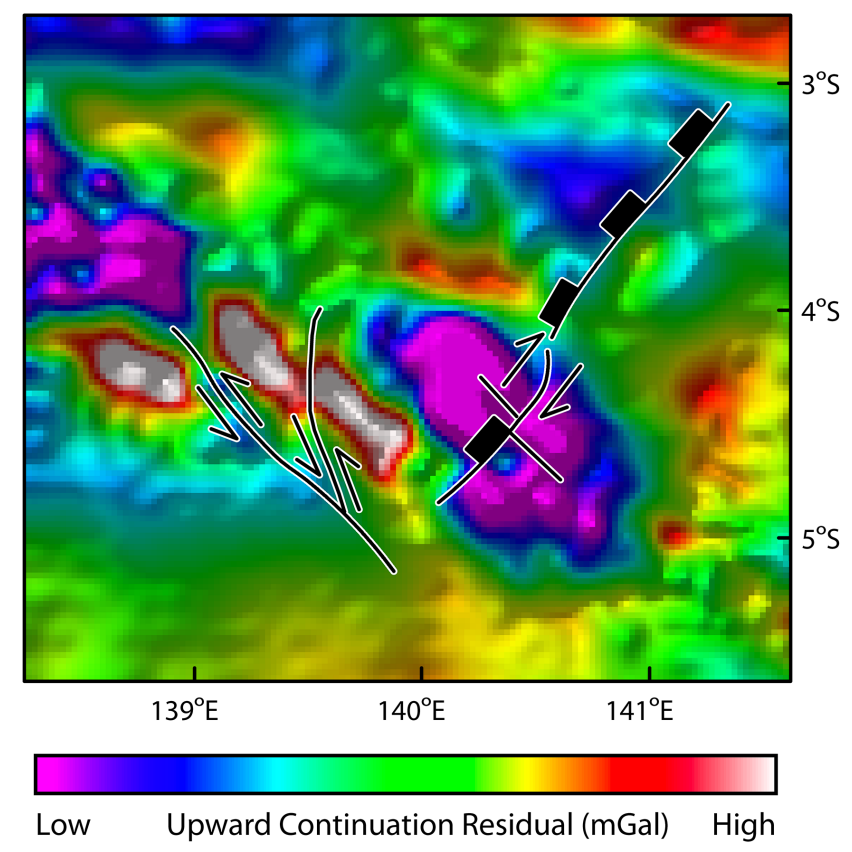

Fig. 9. There were several cases where we could identify lineaments where we could infer an apparent sense of displacement. For example, we show that there may have been some left-lateral displacement of gravity highs (red-white colours), as well as a possible NEtrending extensional fault with a right-lateral sense of movement. The grid that is shown here was generated by subtracting the $40 \mathrm{~km}$ upward continuation (UC) from the $5 \mathrm{~km}$ UC Bouguer grid. The grid is illuminated from the southeast.

however, the mechanism for their formation is disputed. One model for their formation proposes that these are associated with strike-slip or oblique-slip transfer faults (cf. Gibbs 1983, 1984; Lister et al., 1986); the other model proposes that these are zones of accommodation of distributed faulting (cf. Bosworth 1985; Rosendahl et al., 1986; Morley et al., 1990; McClay et al., 2002). Considering (1) that we found no link between what we could identify as deeper-level basement structures in New Guinea and (2) that analogue modelling of rift systems has shown that accommodation zones oriented obliquely to perpendicular to the rift axis are not necessarily related to hard-linked strike-slip basement faults (McClay et al., 2002), it is thus worth considering that the lateral ramps proposed by Hill (1991) for the central Papuan Fold Belt (and beneath the Porgera and Mt Kare gold deposits) are not associated with deeper-level faults and/or an inherited basement fabric. However, if this is the case, it is likely that there is much more to understand about the structural history of the region as there is some apparent NE-SW strike-slip offset of units in this area.

In addition, our analysis of the trend of the basement fabric(s) in this region shows that there is much more variation in the orientation of these structures (Fig. 1d and 10) than what others had proposed earlier (Fig. 1b-c). This means (1) that the arc-normal structures are not related to the dominant structural grain of the Australian lithosphere; (2) that these structures are related to the dominant structural grain of the Australian lithosphere, but have been folded into their current orientation in New Guinea; (3) that these faults are inherited from the Australian lithosphere, but the orientation of the structural grain was always different in New Guinea and Australia; or (4) that the arc-normal structures are unrelated to any existing fabric and are associated with more recent orogenic events. Further work is required to resolve these points.

\subsection{Penetration depth of arc-normal faults}

As the arc-normal lineaments were said to direct metalliferous fluids from deep in the crust, it was important to determine if these were deep faults. This is why we used various UCR filters on magnetic and gravity data sets, and why we looked at seismic tomography data. NNE-trending lineaments were only observed in the higher-frequency UCR filtered magnetic data, indicating that these particular structures are shallow features, or are not magnetic. The UCR filtered gravity data indicate that arc-normal lineaments are also mappable in the high- and low-frequency grids, suggesting that many of the arc-normal lineaments are significant structures that cut through deeper levels of the crust. This idea is supported by seismic tomography data that show that the arc-normal structures might sole into deeper levels of the lithosphere and controlled by deeper lithospheric faults (Fig. 11). This indicates that the arc-normal faults could potentially tap mantle melts and fluids, and this is supported further by the field observations and geochemical data from chains of mantle-derived melts and volcanoes (e.g. Davies 1990, 1991). It is therefore possible that the arc-normal faults control the distribution of metals in New Guinea, but considering our other findings, perhaps only those that are less than 5 million years old.

\subsection{Exploration under cover - mapping the intersection of intrusions and faults}

One of the biggest challenges faced by mineral explorers today is the concept of finding new deposits that do not crop out at the surface. This is especially the case in regions that have very thick soil profiles or within heavily forested regions, such as in New Guinea. Gravity data have long been used as a tool for mineral explorers to infer information about the composition of the basement, where zones of low gravity typically reflect sedimentary basins or felsic intrusions. So we produced a map of the low-gravity zones that were identified in the UCR filtered Bouguer gravity data in the hope that these zones represent zones of felsic to intermediate intrusions - the idea being that explorers might be able to focus their efforts on these regions as they could represent zones where hot metal-bearing fluids and gases associated 


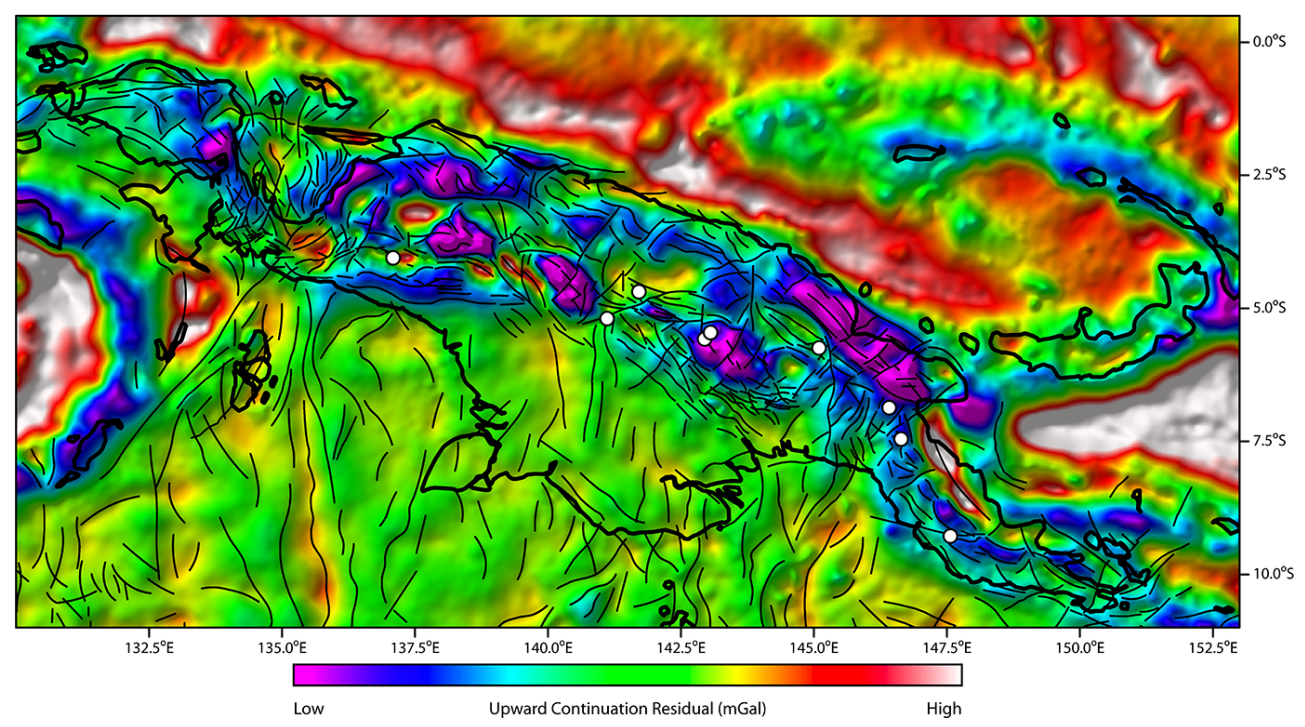

Fig. 10. A new lineament map was generated by interpreting structural features in the free-air, Bouguer and the various UCR filtered gravity data sets. We also compared these interpretations with structural information that was interpreted from the Global Multi-Resolution Topographic data set (Ryan et al., 2009). Here we show the lineament map and the location of major Au/Cu/Ag/Mo deposits draped over the $10 \mathrm{~km}$-minus-50 km UCR filtered gravity grid (illuminated from the southeast). This figure shows not only that the location of some of the $\mathrm{Au} / \mathrm{Cu} / \mathrm{Ag} / \mathrm{Mo}$ deposits (white circles) correlated with identifiable lineaments (transfer faults?), but it also shows that not every deposit is linked with an arc-normal lineament.

with magmatism were once deposited. To examine this, we used the $10-50 \mathrm{~km}$ UCR grid to ensure that we were effectively looking at the gravity signal from a depth of approximately $5 \mathrm{~km}$, in the hope that the zones of lower gravity reflected igneous, rather than sedimentary, rocks (Fig. 12a). This indicates that there are several areas that might represent future exploration targets (Fig. 12a). Explorers might be able to further concentrate their efforts on the low-gravity zones that are intersected by faults, or where faults occur above the gravity anomalies as the structures could act as conduits for fluids and gases, and thus zones where precious metals might come out of solution.

However, there are several problems associated with this approach: (1) the resolution of the gravity data that were available to us is quite coarse (4-5 km), and (2) we do not have much in the way of geological control that could tell us more about the composition of the gravity anomalies. The first problem will only be resolved once more onshore gravity surveys are conducted on New Guinea. We addressed the second problem by comparing the position of low-gravity zones with the Coordinating Committee for Geoscience Programmes in East and Southeast Asia (CCOP) 1:2000 000 geological map of SE Asia (downloaded from http://www. orrbodies.com/resources/item/orr0052), noting the location of felsic intrusives and extrusives and other lithologies at the surface. We then highlighted the areas where the felsic intrusives and extrusives intersected, or were near to the regions of low gravity. While we understand that this cannot be ad- equately tested here, we considered it useful to include this approach, as well as a map so that this might be tested further in the future.

\section{Conclusions}

Our interpretation of the several different geophysical data types indicates that arc-normal lineaments do occur in New Guinea, but these structures are not as prevalent or as simple as they have previously been portrayed. Our approach in using these different data sets means that our interpretation covered some three orders of magnitude in terms of scale (topographic and magnetic data at $\sim 100 \mathrm{~m}\left(10^{2}\right)$; gravity data at 5 to $10 \mathrm{~km}\left(\sim 10^{3}-10^{4}\right)$; and tomography data at $100 \mathrm{~km}$ $\left.\left(10^{5}\right)\right)$. The lineaments were not identified in the highestresolution data and data representing the shallowest levels of the crust (e.g. topographic and magnetic data); however, there was evidence of arc-normal lineaments in the lowerresolution data that imaged deeper levels of the crust (gravity and tomography). Our results show that these lineaments do not intersect every New Guinea gold and copper deposit. Instead, it is only the deposits that are less than 5 million years old that might be associated with arc-normal structural features. These findings mean that exploration geologists might be able to better target which host rocks to investigate for mineralization and that new models are required to explain the genesis of the $>5$ Ma deposits. 

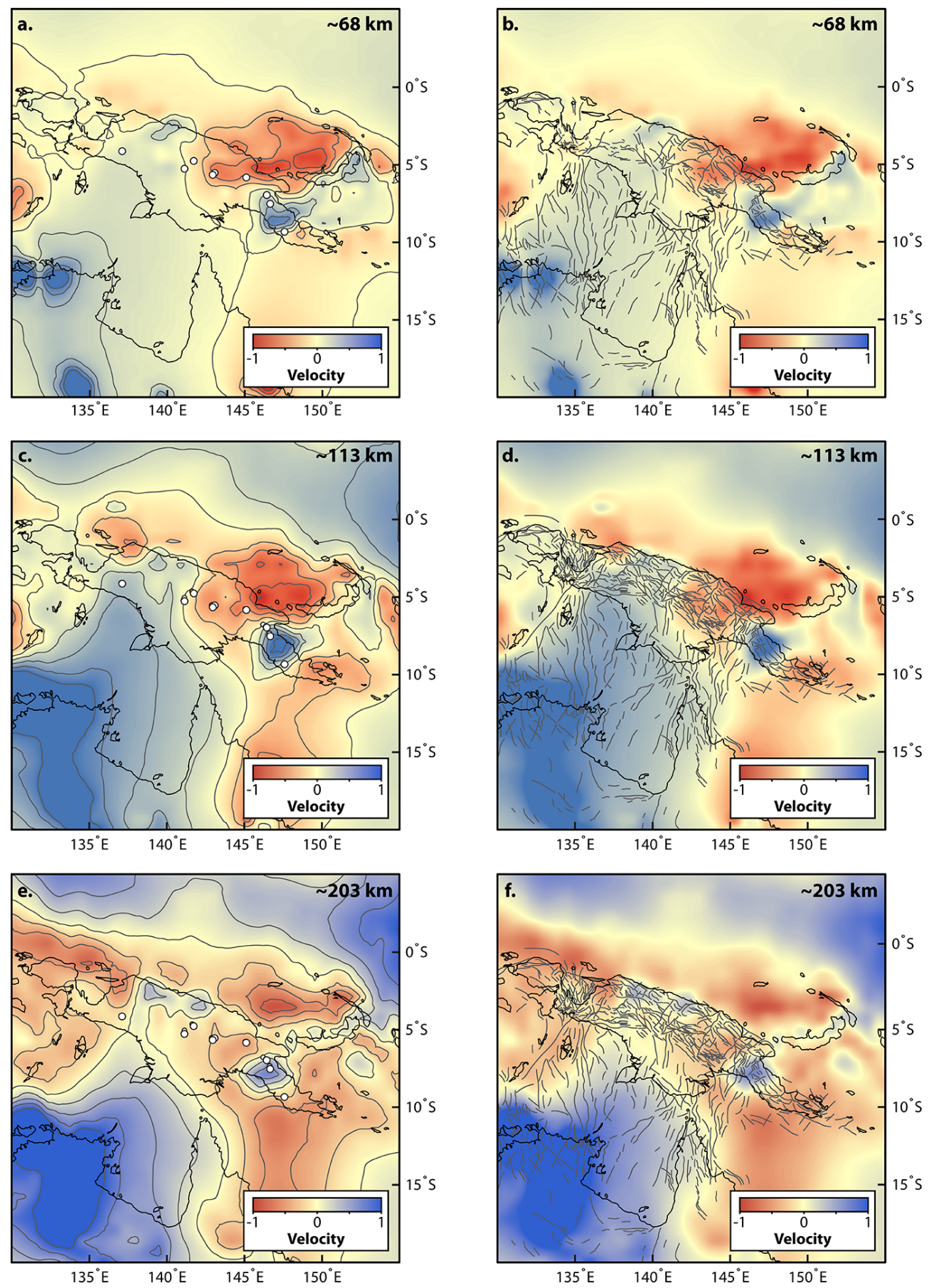

Fig. 11. Seismic tomograms were generated for the New Guinea region from a global $P$ wave tomography data set (Li et al., 2008). Here we show slices at different depths: (a-b) $68 \mathrm{~km}$; (c-d) $113 \mathrm{~km}$; and (e-f) $203 \mathrm{~km}$. The images that are shown in the left-hand column (a, c, e) have been contoured and also show the location of the $\mathrm{Au} / \mathrm{Cu} / \mathrm{Ag} / \mathrm{Mo}$ deposits (white circles) that are described in Fig. 1a. The images that are shown in the right-hand column $(\mathbf{b}, \mathbf{d}, \mathbf{f})$ compare the tomography data with the lineament interpretation that is shown in Fig. 9. There is some similarity between the orientation of some lineaments and the tomographic "anomalies". These tomography data also indicate that there is a keel of cold Australian lithosphere below much of western New Guinea. This possibly represents a rigid indentor. The Grasberg, Frieda River, Nena, Star Mountain and Ok Tedi deposits are located at the margins of this tomographic feature. This might indicate that the edges of the keel have influenced the location of faults in crust, and therefore helped to concentrate the deposition of metalliferous fluids/magmas. 

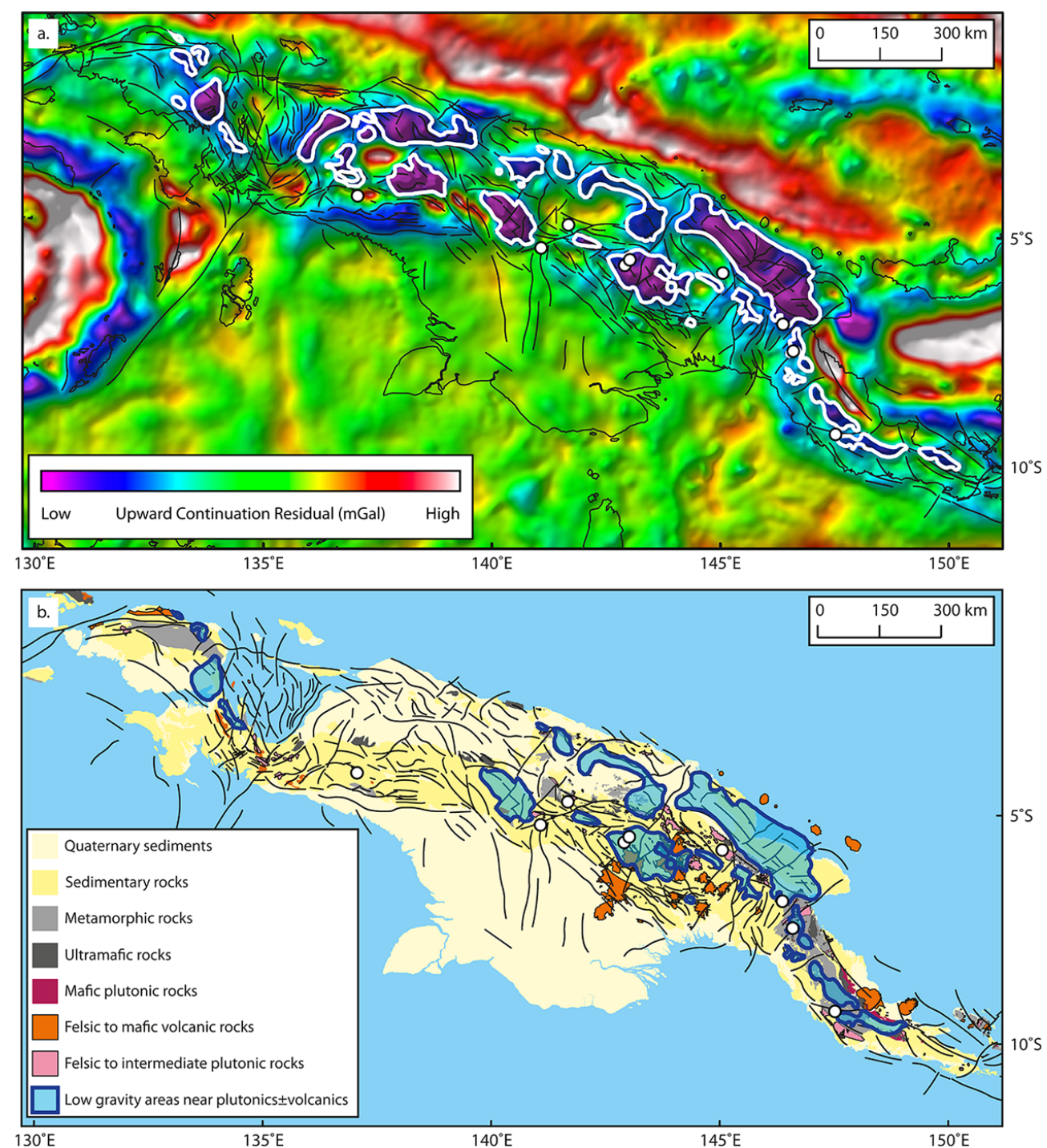

Fig. 12. (a) The $10 \mathrm{~km}$-minus-50 km UCR filtered grid was used to delineate zones of low gravity (white rimmed polygons) in the hope that these regions represented plutons or volcanic feeder zones at depth. These zones of low gravity were compared to (b) the lithologies that are shown on the CCOP 1:2000 000 geological map of SE Asia. The low-gravity zones that were highlighted in (a) that did not correspond with regions of volcanic rocks or felsic to intermediate plutons rocks were deleted to better highlight the regions where plutonic/sub-volcanic rocks might be found at depth, and therefore areas where metalliferous fluids may have been deposited above. The regions that are intersected by arc-normal faults might add further control to where any metalliferous fluids are concentrated.

\section{Supplementary material related to this article is available online at http://www.solid-earth.net/5/163/ 2014/se-5-163-2014-supplement.pdf.}

Acknowledgements. This work was funded by a consortium of mineral exploration companies. L. T. White is also grateful for financial support provided by a consortium of hydrocarbon companies that sponsor the Southeast Asia Research Group at Royal Holloway University of London. The authors thank S. Occhipinti, D. Sewall, C. Swager, G. Cant, M. Roberts, M. Lindsay, N. Hayward, M. Armstrong, M. Cawood, T. Craske, J. Sinclair,
S. Cox, D. Tanner and various people at Geoscience Australia for discussing and commenting on various aspects of this work. The authors would also like to thank Hugh Davies and Kevin Hill for reviewing the paper and the Papua New Guinea Mineral Resources Authority for allowing us to publish images that were generated from aero-magnetic data sets of PNG that were collected by Fugro on behalf of the World Bank (http://www.mra.gov.pg/Investors/ AeromagneticDatasetsArea12,PNG.aspx).

Edited by: C. Gaina 


\section{References}

Amante, C. and Eakins, B. W.: ETOPO1 1 Arc-Minute Global Relief Model: Procedures, Data Sources and Analysis, NOAA Technical Memorandum NESDIS NGDC NGDC-24, 19 pp., 2009.

A.P.C. (The Australasian Petroleum Company Proprietary): The geological results of petroleum exploration in western Papua, Journal of the Geological Society of Australia, 8, 1-133, 1961.

Bosworth, W.: Geometry of propagating continental rifts, Nature, 316, 625-627, 1985.

Corbett, G. J.: Regional structural control of selected $\mathrm{Cu} / \mathrm{Au}$ occurrences in Papua New Guinea, in: Proceedings of the Papua New Guinea Geology, Exploration and Mining Conference: Melbourne, edited by: Rogerson, R., Australasian Institute of Mining and Metallurgy, 57-70, 1994

Davies, H. L.: Structure and evolution of the border region of New Guinea, in: Petroleum Exploration in Papua New Guinea, Proceedings of the First PNG Petroleum Convention, Port Moresby, edited by: Carmen, G. J. and Carmen, Z., Papua New Guinea Chamber of Mines and Petroleum, Port Moresby, 245-269, 1990.

Davies, H. L.: Tectonic Setting of Some Mineral Deposits of the New Guinea Region, AusIMM PNG Geology, Exploration and Mining Conference, 49-57, 1991.

Davies, H. L.: The geology of New Guinea - the cordilleran margin of the Australian continent, Episodes, 35, 87-102, 2012.

Debayle, E., Kennett, B., and Priestley, K.: Global azimuthal seismic anisotropy and the unique plate motion deformation of Australia, Nature, 433, 509-512, 2005.

Dekker, F., Balkwill, H., Slater, A., Herner, R., and Klampschuur, W. A.: Structural interpretation of the eastern Papuan Fold Belt, based on remote sensing and fieldwork, in: Petroleum Exploration in Papua New Guinea, Proceedings of the First PNG Petroleum Convention, Port Moresby, edited by: Carmen, G. J. and Carmen, Z., Papua New Guinea Chamber of Mines and Petroleum, Port Moresby, 319-336, 1990.

DeMets, C., Gordon, R., Argus, D., and Stein, S.: Current plate motions, Geophys. J. Int., 101, 425-478, 1990.

Elliot, C. I.: Australian Lineament Tectonics, unpublished Ph.D. thesis, University of Melbourne, 262 pp., 1994.

Fullea, J., Fernandez, M., and Zeyen, H.: FA2BOUG - a FORTRAN 90 code to compute Bouguer gravity anomalies from gridded free-air anomalies: application to the Atlantic Mediterranean transition zone, Comput. Geosci., 34, 1665-1681, 2008.

Garwin, S., Hall, R., and Watanabe, Y.: Tectonic setting, geology and gold and copper mineralization in Cenozoic magmatic arcs of Southeast Asia and the West Pacific, Econ. Geol., 100th Anniversary Volume, 891-930, 2005.

Gawthorpe, R. L. and Hurst J. M.: Transfer zones in extensional basins: their structural style and influence on drainage development and stratigraphy, J. Geol. Soc. Lond., 150, 1137-1152, 1993.

Gibbs, A. D.: Balanced section constructions from seismic sections in areas of extensional tectonics, J. Struct. Geol., 5, 153-160, 1983.

Gibbs, A. D.: Development of extension and mixed-mode sedimentary basins, in Coward, M. P., Dewey, J. F., and Hancock, P. L. (Eds.): Continental extensional tectonics, Geol. Soc. Special Publication, 28, 19-33, 1984.
Gow, P. and Walshe, J.: The role of pre-existing geologic architecture in the formation of giant porphyry-related $\mathrm{Cu} \pm \mathrm{Au}$ deposits: examples from New Guinea and Chile, Econ. Geol., 100, 819833, 2005.

Hill, K. C.: Structure of the Papuan fold belt, Papua New Guinea, AAPG Bull., 75, 857-872, 1991.

Hill, K. C., Simpson, R. J., Kendrick, R. D., Crowhurst, P. V., O'Sullivan, P. B., and Saefudin, I.: Hydrocarbons in New Guinea, controlled by basement fabric, Mesozoic extension and Tertiary convergent margin tectonics, in: Petroleum Exploration, Development and Production in Papua New Guinea: Proceedings of the Third PNG Petroleum Convention, Port Moresby, 9-11 September 1996, edited by: Buchanan, P. G., 63-76, 1996.

Hill, K. C.: Tectonics, timing and economic deposits in Papua New Guinea (abstract), Australasian Institute of Mining and Metallurgy, Geology, Exploration and Mining Conference, Madang, 10-12 October, Abstracts, 233-234, 1997.

Hill, K., Kendrick, R., Crowhurst, P., and Gow, P.: Coppergold mineralization in New Guinea: tectonics, lineaments, thermochronology and structure, Aust. J. Earth Sci., 49, 737-752, 2002.

Hill, K. C., Keetley, J. T., Kendrick, R. D., and Sutriyono, E.: Structure and hydrocarbon potential of the New Guinea Fold Belt, in: Thrust tectonics and hydrocarbon systems, edited by: K. R. McClay, AAPG Memoir, 82, 494-514, 2004.

Hill, K. C., Bradey, K., Iwanec, J., Wilson, N. and Lucas, K.: Structural exploration in the Papua New Guinea Fold Belt, in: Eastern Australian Basins Symposium III, edited by: Blevin, J. E., Bradshaw, B. E., Uruski, C., Petroleum Exploration Society of Australia, Special Publication, 225-238, 2008.

Hill, K. C., Lucas, K., and Bradley, K.: Structural styles in the Papuan Fold Belt, Papua New Guinea: constraints from analogue modelling, Geol. Soc. Lond., Special Publications, 348, 33-56, 2010.

Jacobsen, B. H.: A case for upward continuation as a standard separation filter for potential field maps, Geophysics, 52, 1138-1148, 1987.

Kendrick, R., Hill, K., Parris, K., Saefudin, I., and O'Sullivan, P.: Timing and style of Neogene regional deformation in the Irian Jaya Fold Belt, Indonesia, Proceedings of the Annual Convention - Indonesian Petroleum Association, 249-262, 1995.

Li, C., van der Hilst, R. D., Engdahl, E. R., and Burdick, S.: A new global model for $P$ wave speed variations in Earth's mantle, Geochem. Geophy. Geosy., 9, Q05018, doi:10.1029/2007GC001806, 2008.

Lister, G. S., Etheridge, M. A., and Symonds, P. A.: Detachment faulting and the evolution of passive continental margins, Geology, 14, 246-250, 1986.

McClay, K. R., Dooley, T., Whitehouse, P., and Mills, M.: 4-D evolution of rift systems: Insights from scaled physical models, AAPG Bulletin, 86, 935-959, 2002.

Milligan, P.: New magnetic datasets to identify energy, geothermal and mineral resources, AusGeo News, September 2010, Issue 99, available at: http://www.ga.gov.au/ausgeonews/ ausgeonews201009/magnetic.jsp (last access: 16 October 2013), 2010 . 
Morley, C.K., Nelson, R. A., Patton, T. L., and Munn, S. G.: Transfer zones in the East African rift system and their relevance to hydrocarbon exploration in rifts, AAPG Bulletin, 74, 1234-1253, 1990.

Morse, M.: Potential field methods prove effective for continental margin studies, AusGeo News, June 2010, Issue 98, http://www. ga.gov.au/ausgeonews/ausgeonews201006/geology.jsp (last access: 16 October 2013), 2010.

Pavlis, N. K., Holmes, S. A., Kenyon, S. C., and Factor, J. K.: An earth gravitational model to degree 2160: EGM2008, EGU General Assembly 2008, Vienna, Austria, 13-18 April, available at: http://earth-info.nga.mil/GandG/wgs84/gravitymod/egm2008 (last access: 16 October 2013), 2008.

Pavlis, N. K., Holmes, S. A., Kenyon, S. C., and Factor, J. K.: The development and evaluation of the Earth Gravitational Model 2008 (EGM2008), J. Geophys. Res., 117, B04406, doi:10.1029/2011JB008916, 2012.

Richards, J.: Lineaments revisited, Society of Economic Geologists Newsletter, 42, 14-20, 2000.
Rosendahl, B. R., Reynolds, D., Lorber, P., Burgess, C., McGill, J., Scott, D., Lambiase, J., and Derksen, S.: Structural expressions of rifting: lessons from Lake Tanganyika, in: Sedimentation in the East African rifts, edited by: Frostick, L. E., Renaut, R. W., Reid, I., and Tiercelin, J. J., Geol. Soc. Special Publication, 25, 29-43, 1986.

Ryan, W. B. F., Carbotte, S. M., Coplan, J. O., O’Hara, S., Melkonian, A., Arko, R., Weissel, R. A., Ferrini, V., Goodwillie, A., Nitsche, F., Bonczkowiski, J., and Zemsky, R.: Global multiresolution topography synthesis, Geochem. Geophy. Geosy., 10, Q03014, doi:10.1029/2008GC002332, 2009.

Smith, R. I.: Tertiary Plate Tectonic Setting and Evolution of Papua New Guinea, in: Petroleum Exploration in Papua New Guinea, p. 229-244, edited by: Carmen, G. J. and Carmen, Z., Proceedings of the First PNG Petroleum Convention, Port Moresby, Papua New Guinea Chamber of Mines and Petroleum, Port Moresby, 1990. 